\title{
A Comparative Analysis of HBV in Korean, Chinese and English*
}

\author{
Chengyu Nan \\ Yanbian University, Yanji, Jilin, China \\ Email: cynan@ybu.edu.cn
}

\begin{abstract}
Human body vocabulary (HBV) is one part of the core vocabulary in Korean, Chinese and English. The fact that Korean, Chinese and English belong to three different types of languages results in some different lexical and semantic features in HBV of the three languages. But due to the common physiological phenomenon and similar experiences shared by the people speaking different languages, Korean, Chinese and English HBV shows some similarities as well. In terms of morphological productivity, HBV of the three languages differs in number, structure and collocation but has the similar processes of word formation, that is, derivation, compounding, conversion, and etc. $\mathrm{HBV}$ of the three languages experiences some similar ways of semantic change as well as semantic asymmetry, such as, transposition, overlapping, misplacement, or vacancy.
\end{abstract}

Index Terms - human body vocabulary, lexical features, semantic features, morphological productivity, semantic shift

\section{LITERATURE REVIEW}

Human body vocabulary (HBV) is one part of the core vocabulary in Korean, Chinese and English. HBV can be classified into four big semantic fields of head, trunk, limbs and viscera. Head can be subcategorized into face, ear, eye, nose, mouth, tooth and tongue; trunk into neck, shoulder, chest, breast, back, abdomen and hip; limbs into hand, arm, leg, foot and knee; and viscera into heart, liver, kidney, lung, stomach and gall bladder.

Scholars have conducted the intra-lingual and inter-lingual research on HBV mainly from the semantic or pragmatic perspective in the early stage and then from the cultural and cognitive perspective in recent ten years. Korean HBV has been studied much earlier (Kang, 1972; Kim, 1976; Lee, 1977) than that of Chinese and English. The studies of Chinese HBV started with the brief introduction (Wang, 1981; Xie, 1981) and non-systematic analysis (Wu, 1988; Zhao, 1993). Recent studies are mostly confined to the cognitive analysis of heart in English and Chinese, discussing three image schema in the conceptual metaphor system of heart (Wang, 2001; Wu, 2004; Qi, 2003, 2004, 2007), the constructing system of cognitive metaphor of heart (Zeng, 2006; Xie, 2007; He, 2008) and the polysemic network of heart (Zhang, 2005, 2006). Cognitive analysis of other HBV, such as face (Zhang, 2003), hand (Gao, 2005), and eye (Jia, 2008) has been done as well. Feng (2008) and Korean scholar Lee (2003) have conducted a general and detailed study of Chinese HBV. Huang (2009) and Zhao (2010) have analysed cognitively the semantic system of HBV in Chinese and English. English HBV has been studied only as examples in the books or articles on cognition (Lakoff \& Johnson, 1980; Lakoff, 1987; Johnson, 1987; Ungerer \& Schmid, 1996; Heine, 1997) with the statement that the whole human body is mapped to the objects and plants around the human beings. Studies of Korean HBV are broader in scope as well, ranging from specific organs, such as mouth (Son, 1990), hand (Yang, 1983; Ma, 1996; Ha, 2005) and eye (Kim, 2006), to the whole (Hong, 1985-1993; Bae, 2001; Lee, 1999, 2006). Korean HBV has also been studied in a comparative way but mainly with reference to Japanese and/or in terms of idioms (Choi, 2003; Choi, 2004). Chinese scholars have done some comparative studies between Korean and Chinese idioms from the cultural perspective (Jin, 1988; Zheng, 2007; Quan, 2008) or from the cognitive perspective (Sun, 2009), as well as cognitive analysis of Korean and English hand (Wen, 2008), cognitive analysis of Korean, Chinese and English eye (Nan, 2011) and the features of Korean, Chinese and English HBV in word formation (Nan, 2012). These studies on Korean HBV have been done mostly in a separate or less systematic way and given inadequate attention by Chinese or western scholars.

In summary, the research of HBV at home and abroad has experienced from macro to micro studies, and from static to dynamic studies. Korean HBV is studied mainly from the lexical and semantic perspective, studies of Chinese HBV and its comparison with English HBV are focused on the cognitive analysis of heart and other parts of human body, while the comparison between Korean and Chinese or English are mainly confined to idioms.

Based on the search for the related usage of HBV in the corpora of Korean, Chinese and English, syntagmatic analysis of Korean HBV will be conducted in both lexical and syntactic level by means of lexical semantics. The focus

\footnotetext{
* This research was supported by the Academy of Korean Studies Grant (AKS-10R-42): Typological Analysis of Korean HBV in Comparative Perspective, and "211" Project of Yanbian University for the third Key Disciplinary Construction: A Comparative Study of English and Korean Word Formation.
} 
of this research is on how Korean, Chinese and English HBV "lives" in real language, that is, morphological productivity, ways of word formation, semantic changes in collocation so as to get better understanding of the features of Korean, Chinese and English HBV.

\section{LexicAl FeAtures of HBV in Korean, ChinESE AND English LANGuAGE}

Korean, Chinese and English HBV is very active in word formation, such as compounding, derivation or conversion. It is also active in collocation, especially unique in the collocation with other HBV or color words.

\section{A. Word Formation}

Korean, Chinese and English HBV, as free morphemes, can form derivatives and compounds while some Korean and Chinese HBV, as bound morphemes, can form derivatives. English HBV can be converted into verbs, adjectives, adverbs or exclamations, Chinese HBV can be converted into prepositions or classifiers.

1. Compounding

All HBV in Korean, Chinese and English can form compounds, most of which are noun compounds, and some verb and adjective compounds. A few adverb compounds of heart can be found in Chinese, e.g. “精心 (carefully)”, “潜心 (with concentration)", and some in English, e.g. "headlong", "shoulder-high", "backstage", "backwards", etc. Compounding of Korean, Chinese and English HBV with some words of color, direction or HBV displays some special lexical and semantic features. For example, Chinese HBV is very rich in compounding two different HBV while English HBV is famous for compounding two same HBV connected with "and " or "to". What's more, compounding of the same HBV and the same color may convey different meanings, or compounding of the same HBV and different colors may have the same meaning. Compounding of HBV and some words of direction are very popular in Korean and Chinese, which is expressed by prepositional phrases in English. Chinese is unique in compounding different kinds of words which are composed of the same morpheme but in different orders. For example, the compounding of stomach and intestines “肠胃” and “胃肠” which have the same meaning, the compounding of hand and under “下手” and “手 下” which means “to act” and “at hand of someone” respectively. Other examples are “头小 (small head)” and “小头 (small part of the whole)”, “手抓 (hold with hand)” and “抓手 (key points)”, and etc.

2. Derivation

Most of Korean, Chinese and English HBV, as free morphemes, can derive new words by the addition of prefixes or suffixes or both. Since Chinese is a type of language with a low morpheme-per-word ratio, it is not so active in derivation as Chinese or English which is the most active in it. By the addition of prefixes, Korean HBV of head and limbs can form noun derivatives only, while English HBV can derive nouns, verbs, adjectives and adverbs, but Chinese HBV cannot form any derivatives with prefixes. By the addition of suffixes, Korean and Chinese HBV can derive nouns only while English HBV can derive nouns, verbs, adjectives and adverbs. By the addition of both prefixes and suffixes, Korean HBV and English HBV can derive nouns and adjectives, which cannot be found in Chinese.

All English HBV can be used only as stems to derive new words. But some Korean and Chinese HBV have been grammaticalized and thus can be used as suffixes to derive new words. Korean "머리 (head)" and "다리 (leg)" can be used as suffixes of nouns, for example, "버르장머리 (manners)", "인정머리 (compassion)", "늙다리 (old person)". Chinese “头 (head)”, “面 (face)” and “手(hand)” can be used as suffixes. “头 (head)” can be suffixes of nouns, verbs and adjectives and either doubles a syllable or derives a noun (e.g. 里头), “面 (face)” can be bound to words indicating direction (e.g. 东面, 前面) and “手(hand)” means “a person with certain profession” (e.g. 选手).

3. Conversion

Conversion is possible for Korean, Chinese and English HBV, but only "머리 (head)" in Korean can be converted and used as a classifier “마리” by vowel change from “- ” to “”, e.g. “돼지 한마리 (a pig)”. Chinese HBV “头

(head）" and “面 (face) " can be converted into conjunctives, meaning the parallel of two actions or two things, e.g. “一面/一头看书，一面/一头掲茶 (drinking tea while reading)”. “头” can be converted into adjectives while “面” into verbs , e.g. “头一天 (the previous day)” and “面谈 (talk face-to-face)”, and “眼 (eye)”, “头” and “面” can be converted into classifiers, e.g. “一眼井 (a well) ”, “一头猪 (a pig)” and “一面镜子 (a mirror)”. English HBV is most active in conversion, which can be converted into verbs, adjectives, adverbs, exclamations or classifier, e.g. "face the truth", "back pay", "sit back", "My foot!", "6-foot high".

\section{B. Collocation}

Same HBV in different languages needs the company of the same or different words. For example, "코 (nose)" in Korean can be collocated with such verbs as "꺽다(bend)”, “빠지다(pull off)”, “꿰이다(pierce)", “납작해지다(flatten)”, “박다(stick)”, while in Chinese “穿(pierce)”, “牵(hold)”, “刮(rub)”, and in English “count”, "pull", "bite", "break", "lead", "pay", "rub", etc. Due to the same physical and physiological reaction of human body to the stimulus, mouth in Korean, Chinese and English can be modified by the same adjectives and mean the same as well. 
For example, “달다, 甜, sweet” and “더럽다, 脏, foul” in Korean, Chinese and English, “바르다, 直(straight)” and “빠르다, 快(quick)" in Korean and Chinese, and "거칠다, crude" in Korean and English. But because of different culture and customs, different adjectives are used to modify mouth in Korean, Chinese and English, for example, “짧다(short)”, “무겁다(heavy)”, “가볍다(light)”, “여물다(ripened)”, “쓰다(bitter)”, “걸다(thick)”, “높다(high)”, “무섭다(frightening)” in Korean, “硬(hard)”, “笨(stupid)”, “长(long)”, “尖(sharp)”, “紧(tight)”, “懒(lazy)”, “软(soft)” in Chinese, and "hungry", “clean”, "loud”, “wide”, "mealy”, "big”, "good/bad”, "poor”, "useless” in English.

Synesthesia is another feature in the collocation of HBV in the three languages. It is a neurologically based condition in which stimulation of one sensory or cognitive pathway leads to automatic, involuntary experiences in a second sensory or cognitive pathway. It often leads to cross-sensory metaphors in languages, wherein the mixing of sensations or the stimulation of one sense that produces a mental impression associated with a different sense, as in the description of one kind of sense impression by using words that normally describe another. For example, “차거운 눈길”, “冷眼” and "cold eye", where the word "cold" which is usually used to describe the sense of touch is employed to describe visual motion. Other examples are “입이 무겁다”, “嘴尖”, “sweet face”, and etc.

\section{Idioms of $H B V+H B V$}

Most of Korean, Chinese and English HBV can collocate with the same or different kinds of HBV to form idioms, among which Chinese idioms of $\mathrm{HBV}+\mathrm{HBV}$ are unique both in number and types.

There are some correspondent idioms of HBV + HBV in Korean, Chinese and English, which have not only lexical meanings, but also metaphorical meanings. For example, the combination of eye and ear forms “눈귀”, “耳目” and "eyes and ears" which all refer to the person who gets information in a secret way. Other examples are "머리부터 발끝까지”, “从头到脚” and “from head to foot”, meaning “covering the whole body”, or “손에 손잡고”, “手拉手” and "hand in hand".

Some Korean idioms are composed of one HBV while the corresponding ones in Chinese and English are composed of two same HBV. For example, “얼굴을 맞대고”, “面对面”, “face to face”, or “어깨를 나란히 하다”, “肩并肩”, “shoulder to shoulder”, or “한마음”, “心连心”, "heart-to-heart”.

Chinese is rich in the idioms of HBV + HBV both in number and types, especially “心 (heart)" which is unique in forming a lot of four-word idioms with other HBV, for example “赤胆忠心 (loyalty)”, “十指连心 (intimately connected)”, “耳软心活 (credulous)” and etc.

\section{Semantic Features of HBV in Korean, Chinese and English Language}

People get to know and then describe new things through something familiar to them. HBV is the most familiar to human beings and therefore used quite often to describe some new concrete and abstract things, which enables the meanings of HBV has been extended. But the degree and scope of extension are different in Korean, Chinese and English.

\section{A. Semantic Extension}

By means of metaphor and metonymy, the meanings of most HBV in Korean, Chinese and English have been mapped from human body domain to non-human body domain, such as color domain, time and space domain, emotional domain, and thus refer to space, time, feelings, attitudes, manners, and etc. with the help of certain nouns, verbs, adjectives or prepositions.

1. Certain kinds of person or thing

Korean, Chinese and English HBV can be used metonymically to refer to people, a person with certain features or certain skills or abilities, wherein a specific part of something is used to refer to the whole. For example, such parts of a person as “새 얼굴 (new faces)”, “新手 (green hand)” and "old bones" are used to describe certain kind of people. “주먹코 (bulbous nose)”, “메기입 (wide mouth)”, “蒜头鼻 (bubble nose)”, “blue eyes” and “loudmouth” refer to a person with certain appearance or personality, while “눈귀 (private eye)”, “千里眼 (farsighted person)” and “silver tongue" refer to someone with a special skill. The principle of least effort is employed in this case. People will naturally choose the most convenient way or the path of least resistance to understand and describe new things. In the above-listed examples, a certain part (face, hand or bones) or nature (skill or ability) of a person is used to substitute for a person. Korean, Chinese and English HBV can also be used metaphorically to refer to something with the shape or function of certain organ, for example, “바늘귀 (eye of a needle)”, “감자눈 (eye of potato)”, “火舌 (tongues of flame)", “针鼻 (eye of a needle)”, “mouth of the river", "nose of plane" and etc.. 


\section{Space and time}

In Korean, Chinese and English, heart can mean “center”, for example, “국가행정의 심장부”, “市中心”, “heart of city". Some HBV in Korean, Chinese and English, collocated with some prepositions of space, refer to short distance or short time. For example, “코아래 입”, “눈코 사이”, “眼皮/鼻子底下”, “before/in front of one’s (very) eyes” and “under one's nose” mean short distance, while “눈앞”, “코앞”, “眼前”, “眼下”, “before hand” and “in the twinkling of an eye" mean short time. Head is also used metaphorically in the three languages to refer to "the starting time of something" or "the front part of something", for example, "침대머리 (head of a bed)", "해질머리 (start of the sunset)”, “船头 (bow of a ship)”, “从头到尾 (from beginning to end)”, "head of the stairs” and "have a good head for business". Nose can convey the same meaning in Chinese and English, for example, “鼻祖 (originator)” and “nose of a plane".

3. Feelings

One of the main features of viscera is "inner" or "inside", which determines its extended meaning of "inside world", that is feeling or thought. Apart from kidney and stomach, other components of viscera can mean feelings or emotions in Chinese, most of which can be conveyed only by heart in English, a few by stomach or kidney. English compounds or idioms of heart with the meaning of feeling can find their equivalence with Chinese ones of different components of viscera, e.g. “肺腑之言（words from the bottom of one's heart）”, “互诉衣肠 (heart-heart-talk) ”, “热心肠 （warm-hearted）”, “肝肠寸断 (heartbroken) ”, “胆小如鼠（chicken-heart）, “心肝（sweet heart）”. Chinese “心 (heart)" has the meaning of thought, which is expressed in English by “mental”, e.g. “心算 (mental calculation) ”.

Five sense organs are often used in the idioms showing one's such feelings as anger, horror, sadness or happiness. When someone is angry, he will “눈을 부릅뜨다 (with eyes wide open)”, “咬牙切齿 (grit one’s teeth)”, or “jump down one's throat”. When someone is happy, he will, “입이 찢어지다 (grin from ear to ear)”, “合不拢嘴 (grin from ear to ear)", or “smile from ear to ear”, but “코를 실룩거리다 (have a lump in one’s throat)”, “触目伤心 (heart-breaking)" or "down in the mouth" when he is sad, and “입이 얼어붙다 (mouth-frozen)”, “目瞪口朵 (stare openmouthed)", "tongue-tied" when he is frightened.

4. Attitudes and manners

When someone behaves as if he were more important than other people, he would naturally look up or down. Therefore, the collocation of HBV with words like high or air is used to describe a haughty person, for example, "눈이 높다 (high eye)”, “코가 높다 (tall nose)”, “鼻孔朝天 (with one’s nose in the air)”, “眼高手低 (high eye)” or “with one's nose in the air", and the collocation of HBV with words like lower or down is used to show one's arrogance, for example, “눈을 깔다 (eyes down)”, “下眼相看 (eyes down)” or “look down one’s nose at”.

\section{B. Semantic Shift}

Both semantic symmetry and asymmetry exist in the expressions with HBV in Korean, Chinese and English. To express the meaning of many people, we have the same phrase in the three languages, “입이 많다”, “嘴多”, “many mouths", where mouth is used to mean people. Other examples are “입가에 거품을 물다”, “口吐白沫”, “foam at the mouth”, or “입을 열다/떼다", “开口”, “open one’s mouth”.

Arbitrariness between the signifier and the signified result in semantic discrepancies among Korean, Chinese and English HBV, by means of which semantic shifts or semantic asymmetry arise among the lexical equivalents of Korean, Chinese and English HBV. According to Oxford Advanced Learner's Dictionary, asymmetry is the appearance of something whose two sides or parts are not the same in size or shape. Semantic asymmetry occurs mainly when two words or phrases sharing the same conceptual meaning display different associative meanings or when the same associative meaning is expressed by different words or phrases.

1. Semantic Transposition

Semantic transposition across languages takes place when the same associative meaning is expressed by different words or phrases in different languages. To express the meaning of not acting in a way that supports what one says that he believes, the combination of mouth and belly ("입다르고 배다르다") is used in Korean, , the combination of mouth and heart (“口是心非”) is used in Chinese, and face ("two-faced”) is used in English. Another example is that nose (“코를 박다”), head (“埋头”) and eye (“be up to one's eyeballs in sth.”) are used respectively in Korean, Chinese and English to express the meaning of being busy with.

2. Semantic Overlapping

Semantic overlapping takes place when the semantic range of a word or phrase in one language partly covers that in 
other languages. For example, Korean "머리” and Chinese "头” cover the meaning of both head and hair in English. Therefore, when we say "wash hair" and "shake head" in English, the same word is used in Korean ("머리를 감다" and “머리를 흔들다”) and Chinese (“洗头” and “摇头”). Here are some more examples. “입이 달다” "“嘴甜” and "sweet mouth" are all composed of mouth and sweet, and have the same associative meaning of engaging in flattery, but "입이 달다" ranges more semantically, meaning having good appetite.

3. Semantic Misplacement

Semantic misplacement occurs in the seemingly equivalents, that is, when the same form in different languages has different associative meanings. For instance, “고개가 수그러지다”, “低头” and "get one's head down” have the same combination of head and down, and the same conceptual meaning of lowering one's head, but their associative meanings are totally different. "고개가 수그러지다" means respect or admiration, "低头” means yielding and "get one's head down" means avoiding attracting attention. Another example is “머리가 크다 (grown up)", “头大 (dizzy or powerful)" and "big-headed (arrogant or conceited)", which are all the combination of head and big.

4. Semantic Vacancy

Semantic vacancy occurs when a word or phrase has an associative meaning in one language but only a conceptual meaning in other languages. “입이 쓰다”, “嘴苦” and "bitter mouth” are equivalent both in expression and conceptual meaning of having bitter smell in the mouth because of abnormal condition in alimentary system, respiratory system or cardiovascular system. But the first one has an associative meaning of having bad appetite or bad mood. It shows that physiological conditions can cause the effect on psychological condition. Other examples are “발이 차갑다”, “脚凉” and "have cold feet" are equivalent both in form and conceptual meaning, but the English one has figurative meaning of having a feeling of worry that is strong enough to make someone reconsider the plan.

\section{CONCLUSION}

Typologically, Korean, Chinese and English belong to three different types of language. Korean is agglutinative, Chinese is isolating and English is inflectional analytic. Therefore, HBV shows some different lexical and semantic features in Korean, Chinese and English. In terms of morphological productivity, HBV of the three languages differ in number and structure, while in terms of collocation, due to different cultures and thinking modes, there exist semantic asymmetries, such as transposition, overlapping, misplacement, or vacancy. On the other hand, common physiological phenomenon and similar experiences make the people speaking different languages have the similar cognitive styles, which can be seen in the similarities of Korean, Chinese and English HBV in word formation, collocation and semantic change.

\section{REFERENCES}

[1] Bae, Doyoung. (2001). Meaning Extension of Korean HBV. Ph.D dissertation, Pusan University of Korea.

[2] Bullon, Stephen. (2006). Longman Dictionary of Contemporary English (4th ed.). London: Pearson ESL.

[3] Chinese Comprehensive Dictionary. (2010). Shanghai: Shanghai Dictionary Press.

[4] Comrie, B. (1981). Language Universals and Linguistic Typology. Oxford: Blackwell.

[5] Cruse, D. A. (1986). Lexical Semantics. Cambridge: Cambridge University Press.

[6] Feng, Lingyu. (2008). On Chinese HBV. Beijing: China Broadcasting and Television Publishing House.

[7] Johnson, M. (1987). The Body in the Mind: The Bodily Basis of Meaning, Imagination and Reason. Chicago: University of Chicago Press.

[8] Lakoff, G. \& M. Johnson. (1999). Philosophy in the Flesh - the Embodied Mind and Its Challenge to Western Thought. New York: Basic Books.

[9] Lee, Kyoungja. (1999/2006). Formation of Korean HBV 1/2. Seoul: Chongnam University Press.

[10] Lee, Hyenok. (2003). On Chinese HBV. Beijing: Zhongguo Gongren Press.

[11] Leech, G. (1981). Semantics. Harmondsworth: Penguin.

[12] Nan, Chengyu. (2011). Cognitive Study of Metaphorical Usage of Visual Organ in Korean, Chinese and English. Journal of Yanbian University, 2, 75-78.

[13] Nan, Chengyu. (2012). Features of Korean, Chinese and English HBV in Word Formation. Korean Language in China, 1, $19-24$.

[14] The National Institute of The Korean Language. (1999). Korean Dictionary. Seoul: Doosan Donga.

[15] Vanhove, M (ed.). (2008). From Polysemy to Semantic Change: towards a typology of lexical semantic association. Amsterdam: John Benjamins Publishing Co.

Chengyu Nan was born in Yanji, China in 1965. She received her Ph. D degree in Linguistics from Yanbian University, China in 2007. 
She is currently an associate professor and vice dean in the College of Foreign Languages, Yanbian University, Yanji, China. Her research interests include FLT and comparative study of English and Korean language. She has published two books: English Education of Korean-Chinese (2004) and A Comparative Study of Tense and Aspect in Korean and English languages (2007). She has published some papers on English and Korean tense and aspect, word formation in Korean and English, teaching English to Korean-Chinese bilinguals, and HBV in Korean, Chinese and English.

Dr. Nan is a member of International Association for Applied Linguistics and a member of KATE (Korea Association of Teachers of English). 